\title{
Another Philadelphia story*
}

Jerald P. Radich

Fred Hutchinson Cancer Research Center, Seattle, WA; USA

E-mail: jradich@fredhutch.org

doi:10.3324/haematol.2021.280581

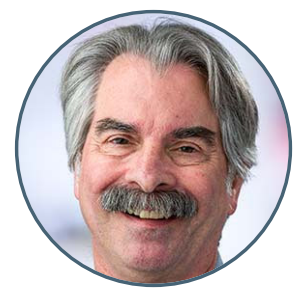

*"The Philadelphia Story" is a classic 1940 American romantic comedy starring a blockbuster lineup of Katharine Hepburn, Cary Grant, and James Stewart.

THTE A minute chromosome in human chronic granulocytic leukemia.

\section{AUTHORS Nowell PC, Hungerford DA}

JOURNAL Science 1960;132:1497.

$\mathrm{P}$ hiladelphia, in the USA, is a city steeped in history. It was in Philadelphia that the Declaration of Independence and the US Constitution were signed. The Philly cheesesteak sandwich was born there, and Benjamin Franklin died there (presumably not from the sandwich). In 1960, Philadelphia was also home of Drs. Peter Nowell, a pathologist at the University of Pennsylvania and David Hungerford, a graduate student at the Institute for Cancer Research.

1960 was an eventful year. In the USA, John Kennedy was elected president, and 3,500 troops were sent to Vietnam, initiating a grueling and divisive 13-year war. The Olympic Games, held in Rome, were televised for the first time. Alfred Hitchcock made the horror classic, Psycho. And tucked in the Journal Science was a modest, two paragraph, 243word abstract that would revolutionize the field of genetics and cancer, entitled "A minute chromosome in human chronic granulocytic leukemia." The piece described a recurrent chromosomal abnormality found in seven cases of chronic granulocytic (now, myelogenous) leukemia. No other chromosome abnormalities were found in the cases, and some cells had a normal karyotype, suggesting that the new chromosome was not constitutional. The abstract con- cludes with the understated blockbuster, "The findings suggest a causal relationship between the chromosomal abnormality observed and chronic granulocytic leukemia."

Earlier in 1960, Nowell and Hungerford had previously reported on two of these cases in a paper that included cases of acute and chronic leukemia, in which they suggested the minute chromosome might be an altered Y. In the Science abstract, five more cases of chronic myelogenous leukemia (CML) were added and, remarkably, each had the altered chromosome, making this the first demonstration of a consistent chromosomal abnormality found in a specific type of cancer. The rival cytogenetic research group in Edinburgh proposed that the chromosome be dubbed "the Philadelphia chromosome."

In Peter Nowell's own underplayed words, "the next decade was frustrating." Further identification of the chromosome awaited the advent of new banding techniques in the 1970s pioneered by Janet Rowley, which demonstrated that the Philadelphia chromosome was actually a reciprocal translocation between chromosomes 22 and 9. Jump another decade into the 1980s, and the story is further detailed with the discovery that the translocation fused the $B C R$ region from chromosome 22 with the human homologue of the
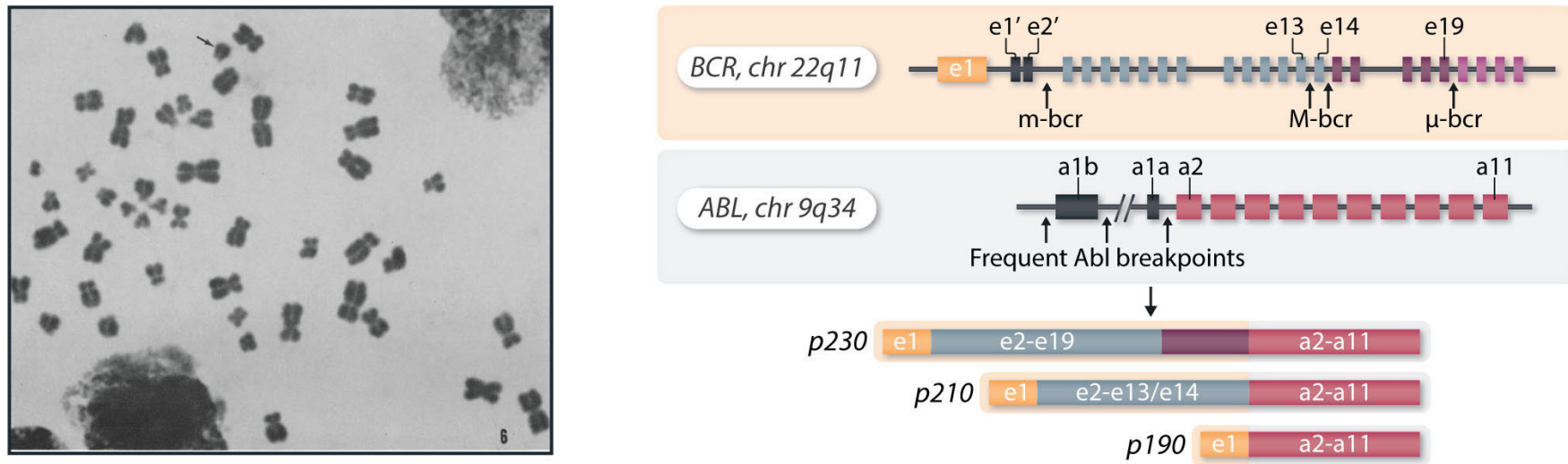

Figure 1. The Philadelphia chromosome. The left panel is the first image of the Philadelphia chromosome from Nowell and Hungerford's first paper. ${ }^{5}$ This was initially thought to be a $Y$ chromosome. The right panel shows the breakpoints involving the $B C R$ gene from chromosome 22 , and the $A B L$ gene from chromosome 9 . The bottom right panels show the fusion mRNA breakpoints found in leukemia. 
recently discovered $v$-ABL gene. ${ }^{3}$ A further decade leap into the 1990s and it was demonstrated that $B C R-A B L$ did indeed cause leukemia in a murine model. ${ }^{4}$ The foundation of "precision medicine" had been laid.

CML is perhaps the best example of the old "bench to bedside" adage and is an excellent model of the power of precision medicine since $B C R-A B L$ is a target of treatment, and a biomarker of response. Soon after the invention of the polymerase chain reaction, $B C R-A B L$ mRNA was used to track disease response and predict relapse following allogeneic transplantation. Tyrosine kinase inhibitors were found to inhibit $B C R-A B L$ in vitro and were soon championed into the clinic. The combination of having a remarkably effective drug and a remarkably robust way of monitoring response completely changed the natural history of CML from a disease associated with a median lifespan of $<7$ years to one where patients now enjoy essentially a normal lifespan. It is difficult to underestimate the accomplishments of these scientists and patients over a relatively short period of time.

In 1776 a revolution officially began in Philadelphia. In 1960 , another one started.

\section{References}

1. Nowell PC, Hungerford DA. A minute chromosome in human chronic granulocytic leukemia. Science. 1960;142:1497.

2. Rowley JD. A new consistent chromosomal abnormality in chronic myelogenous leukaemia identified by quinacrine fluorescene and Giemsa staining. Nature. 1973;243(5405):290-293.

3. De Klein A, van Kessel AG, Grosveld G, et al. A cellular oncogene is translocated to the Philadelphia chromosome in chronic myelocytic leukaemia. Nature. 1982;300(5894):765-767.

4. Daley GQ, Van Etten RA, Baltimore D. Induction of chronic myelogenous leukemia in mice by the P210 bcr/abl gene of the Philadelphia chromosome. Science. 1990;247(4944):834-830.

5. Nowell PC, Hungerford DA. Chromosome studies on normal and leukemic human leukocytes. J Natl Cancer Inst. 1960;25(1):85-109. 